HYPOTHESIS

\title{
A fibrin based model for rheumatoid synovitis
}

\section{O Sánchez-Pernaute, R Largo, E Calvo, M A Alvarez-Soria, J Egido, G Herrero-Beaumont}

Ann Rheum Dis 2003;62:1135-1138. doi: 10.1136/ard.2003.011767

Intracavitary fibrin clots may initiate pannus formation and the immunopathology of RA. Two critical steps, probably host dependent, may determine the development of RA: an altered regulation of extravascular haemostasis or an aberrant reactivity of synovial fibroblasts to the adhered fibrin clots. Current treatments for RA target events downstream of fibrin deposition, perhaps agents acting at an earlier stage should be tried.
See end of article for authors' affiliations

a thors affilitions

Correspondence to: Dr O Sánchez-Pernaute, Rheumatology Section, Fundación Jiménez Díaz, Avda Reyes Católicos 2, 28040 Madrid, Spain; OSanchez@fjd.es

Accepted 14 July 2003 c urrently, it is considered that mononuclear cells recruited to the sublining are the principal inducers of synovial cell activation in rheumatoid arthritis (RA). ${ }^{1}$ None the less, a small amount of evidence of $\mathrm{T}$ cell mediators at the start of the disease has led some experts to suggest that joint destruction and recruitment of immunocompetent cells may rely on innate processes primarily involving synovial fibroblasts. $^{2}$ These cells are arranged at the intimal lining as an epithelium, separating a cavity from a substratum. The cavity acts as the final receptacle for cell debris and exudates resulting from the cascade of intrasynovial inflammatory events. Because of the accumulation of cytokines, free radicals, or metalloproteinases at this site, processes at the cavity have a role in disease amplification. In addition to its contribution to disease progression, we propose that both inflammatory and immunological processes of RA are initiated at the joint space and result from the activation of synovial fibroblasts by their contact with intracavitary fibrin. Figure lA shows the pathogenic sequence that we propose. In parallel with the scheme, fig $1 \mathrm{~B}$ shows the microarchitecture of areas associated with fibrin deposition in a representative rheumatoid synovial tissue.

COAGULATION INSIDE THE JOINT SPACE The rheumatoid process may be started by any external factor which can induce joint swelling. ${ }^{1}$ As major candidates, several viruses, mycoplasms, mycobacteria, and enterobacteria have been evoked. Genetic factors associated with the appearance of RA and its severity would contribute at this point by selecting susceptible hosts to develop a severe enough response to potential aggressors. ${ }^{3}$ From the beginning of the inflammatory reaction, plasma components, including fibrinogen and zymogens, drain to the joint cavity (fig 1A, step 1). Several inflammatory mediators have the ability to cleave zymogens to their active form, triggering haemostasis and fibrin clotting inside the joint space (fig lA, step 2 ). Indeed, there is evidence of activation of both extrinsic and intrinsic pathways of haemostasis in the synovial fluid (reviewed by Busso and Hamilton $^{4}$ ). But haemostasis activation seems to be a "normal" response to joint injury, because it occurs in other inflammatory conditions. ${ }^{5}$ What may differentiate RA from other joint diseases is an imbalance between coagulation and fibrinolysis within the rheumatoid joint. ${ }^{6-8}$

\section{"An imbalance between coagulation and fibrinolysis may be present in RA"}

Most likely, non-rheumatoid hosts can maintain a proportional rate of fibrin formation and dissolution that facilitates clearance of the inflammatory exudates. Rheumatoid patients, on the other hand, have difficulties in the removal of fibrin clots. ${ }^{9-11}$ This imbalance is not dependent on the existence of an inefficacious plasminogen system in rheumatoid hosts, and in fact fibrinolysis seems reasonably activated in their joints. ${ }^{12}$ Several factors can account for the difficult dissolution of fibrin clots. For instance, it has been shown that a significant amount of the single chain urokinase (scuPA) molecule present in the synovial fluid from patients with RA is cleaved by thrombin into a two chain form (tcuPA/T), which is inactive as a plasminogen activator. Presumably, tcuPA/T maintains its affinity for the urokinase cell receptor (UPAR), and could act through this pathway as a mediator of tissue damage. ${ }^{13}$ Additionally, inhibitors of the plasminogen system are more abundant in rheumatoid than in non-rheumatoid synovial fluids. ${ }^{14}{ }^{15}$ Whatever mechanisms are involved, the final result of this imbalance is that, in patients with RA, fibrin clots tend to increase in size, and are subsequently deposited on the synovial intima (fig lA, step 3). ${ }^{16-18}$

\section{ROLE OF FIBRIN DEPOSITS IN THE ACQUISITION OF AN INVASIVE PHENOTYPE}

Adhesion of fibrin clots to the synovial surface may induce migration of intimal cells into and around the deposits (fig lA, step 4), as we have recently shown in antigen induced arthritis. ${ }^{19}$ In this experimental model, invasion of the deposits by synovial cells ended with a complete encircling and incorporation of fibrin into the tissue. Migration of fibroblasts through fibrin matrices

Abbreviations: MMPs, matrix metalloproteinases; PA, plasminogen activator; RA, rheumatoid arthritis 

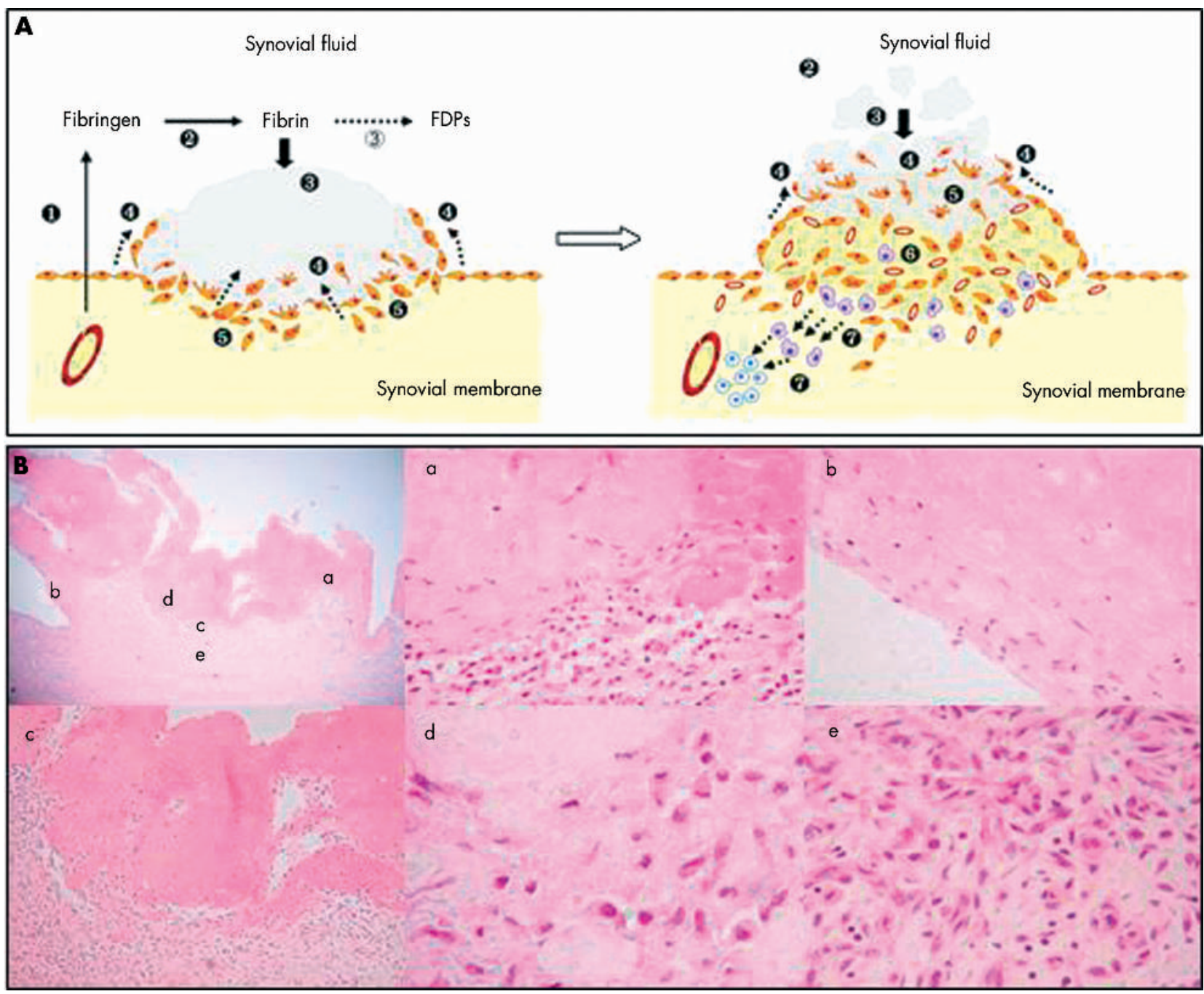

Figure 1 Pathogenesis of RA as a fibrin induced disease. (A) The figure shows two sequential panels; the numbers indicate the pathogenic steps leading to established RA. 1. Exudation of fibrinogen and clotting factors to the joint space follows joint swelling. 2. Haemostasis activation within the cavity leads to fibrin formation. 3. Fibrin clots are partially removed by the plasminogen system (unfilled circle), but most of them get stuck to the synovial intima (black circle). 4. Cells at the fibrin-synovium interface migrate into and around the deposits (arrows). 5. Clot components induce multiple activating pathways in synoviocytes by the coupling of specific receptors. These include proliferation, secretion of proteinases, and synthesis of proinflammatory mediators. 6. A fibroproliferative tissue appears underneath the front of migrating cells, as a result of remodelling of the invaded clots by activated cells. In this area, macrophages and blood vessels are increased owing to the release of growth factors and chemokines. 7. Remodelling induces modifications in the structure of fibrin chains, which become immunogenic. Epitopes from these transformed autologous peptides are presented to T lymphocytes, which in turn initiate a specific immune reactivity against them. As illustrated in the right panel, continuous deposition of fibrin clots and the advance of the front of migration account for tissue hypertrophic growth at the areas of attachment. (B) Left upper panel: photomicrograph of a rheumatoid synovial membrane stained with haematoxylin-eosin $(x 40)$. The image shows a large eosinophilic deposit of fibrin adhering to the synovial tissue. Areas indicated with the letters a to e are magnified in the following panels. (a) A detail of cell migration into the deposit $(\times 200)$. (b) The deposit shows a partial epithelisation at the margin of attachment with the tissue $(\times 400)$. (c) The interface area is magnified $(\times 100)$ to see the sharp differences of microarchitecture and cellularity at both sides. (d) Over the interface shown in (c), cells are scattered and have various shapes and sizes. Some of them are undergoing mitosis. The interstitium is predominantly amorphous $(\times 1000)$. (e) At the base of the clot, the tissue looks fibrotic, hypercellular with fibroblasts and mononuclear cells, and rich in microvasculature. Some fibroblasts are undergoing mitosis. FDPs, fibrin(ogen) degradation peptides.

is a naturally occurring phenomenon in wound healing processes, and also likely to take place in RA. The ability of fibronectin to cross link fibrin matrices, found both in wounds and in the inflamed joint, may be relevant for the induction of fibroblast invasiveness. ${ }^{20-22}$ Fibronectin provides binding sites for cell attachment, and dynamic interactions between integrins and their matrix ligands allow fibroblast locomotion through the network. ${ }^{23}$ Interestingly, in RA, fibrin-fibronectin complexes have been associated with pannus formation and with an erosive tendency. ${ }^{24} 25$

"Adhered fibrin clots may act as scaffolds for pannus formation"
Indeed, fibrin deposits could constitute the substrate for pannus development, eliciting several activation pathways in synovial fibroblasts (fig lA, step 5). Pannus is defined as a transformed tissue, rich in synovial fibroblasts and interstitial matrix, fibrotic, hyperplasic, and invasive. It is not uniformly distributed throughout the rheumatoid synovium, but appears as focal hypertrophic areas frequently close to cartilage erosions. According to our model, pannus would form around adhered fibrin clots, which would act as scaffolds for synovial focal growth. ${ }^{26-28}$ As long as there is fibrin clotting inside the joint space, this mechanism of synovial growth may self perpetuate through the adhesion of new fibrin and its invasion by migrating cells. Moreover, 
several clot components, such as thrombin, urokinase, and matrix glycoproteins, can induce cell proliferation, and trigger the expression of cytokines and inflammatory mediators through the binding of surface receptors of synovial fibroblasts. ${ }^{29-33}$ Some features related to pannus, such as angiogenesis and recruitment of macrophages, may appear as the response to cell interactions with clotting factors and fibrinogen. ${ }^{34}{ }^{35}$ With regard to the aggressive behaviour of the transformed tissue, the interaction between fibrin and infiltrating fibroblasts results in the coexistent activation of different proteolytic pathways which are potent effectors of joint destruction, especially the plasminogen system and the family of matrix metalloproteinases (MMPs). There is certain overlapping in the functions of these groups of proteins; thus, while thrombin and uPA can erode cartilage and the extracellular matrix, ${ }^{36}$ most MMPs display fibrinolytic activity. ${ }^{37}$ Both the UPA-uPAR complex and the membrane anchored MMPs have been implicated in the pericellular matrix degradation necessary for the fibrininvasive activity of fibroblasts. Additionally, plasminogen activators may cleave pro-MMPs to their active forms, thus increasing the destructive potential of fibrin areas infiltrated by fibroblasts. ${ }^{38}$

\section{INTRASYNOVIAL DIGESTION OF FIBRIN MATRICES MAY ACCOUNT FOR IMMUNOGENESIS IN RA}

The synovial fibroblasts primed by their contact with fibrin constitute a front of cell migration moving towards the luminal surface of the deposits. As a consequence of cell advance, fibrinous material becomes incorporated to the synovium (fig 1A, step 6). Figure 1B illustrates the typical synovial microarchitecture under a fibrin deposit, in which a fringe of hypercellular scarring tissue appears between the deposit and normal synovium. This granulation tissue presumably results from progressive remodelling of the incorporated fibrin by interstitial fibroblasts and macrophages recruited to these areas.

\section{"Insolubility of fibrin accounts for a prolonged exposure of its residues to immunocompetent cells inside the joint"}

Acquisition of autoantigenicity by components of the fibrin networks may be a direct consequence of tissue remodelling (fig 1A, step 7). Autologous proteins need to undergo modifications in their molecules to become immunogenic. Because fibrin is an insoluble protein, its degradation inside the synovium is a laborious process, and clearance of its residues is difficult in comparison with clearance of soluble substrates. These facts favour the appearance of structural alterations in fibrin chains and their prolonged exposure to immunocompetent cells inside the joint. In the inflamed environment part of the fibrin degradation is carried out by the action of MMPs, instead of through the constitutive route dependent on plasmin. This may account for the generation of new epitopes in the molecule of fibrin. ${ }^{37}$ Another mechanism of protein transformation, which may facilitate proteolytic cleavage of the substrate, is citrullination. This process consists of the substitution of arginine residues by citrulline, by the enzyme arginine peptidyl deiminase. Not only are citrullinated forms of the fibrin chains found inside the inflamed synovium ${ }^{39}$ but also the production of antibodies against citrullinated substrates is being recently recognised as specific to $\mathrm{RA}^{40}$ On the whole, this suggests that digestion of fibrin networks generates transformed peptides that can be phagocytosed and subsequently externalised at the surface of antigen presenting cells for the recognition of $\mathrm{T}$ lymphocytes. The latter would further orchestrate the immunological response typical of established RA.

\section{CRITICAL STEPS IN THE FIBRIN INDUCED PATHOGENIC SCHEME OF RA}

In summary, according to our proposition, RA is an inflammatory state which generates an excess of intracavitary fibrin, and the typical processes of the disease are due to the interaction of fibrin clots with intimal cells. It is likely that the formation of intracavitary fibrin clots or even their interaction with the intimal layer happens in a non-specific way after the incidence of any triggering agent. The development of RA could then occur in those hosts with a genetically determined alteration of extravascular haemostasis, leading to an excessive local fibrin formation. On the other hand, individual factors probably play a part in determining the cellular response to the adhered fibrin clots. An aberrant response resulting in the rheumatoid transformation could be due to multiple mechanisms, such as an overexpression of adhesion molecules or an abnormal generation of proinflammatory isoforms of fibronectin. Because migration of synovial fibroblasts into the fibrin networks is central to the pathogenic process here described, mechanisms controlling fibroblast locomotion could also be important in patients with RA. None the less, patients with RA do not show relevant alterations in their systemic coagulation activity or in their wound healing processes outside the joint. Hence, any of these alterations must be restricted to the inflamed environment, or possibly induced by the initiating agent.

According to the pathogenic sequence we propose here, current treatments for RA target events downstream of fibrin deposition. It would be interesting to test the clinical efficacy of agents that might act at earlier stages in the disease process, such as anticoagulants, blockers of cell-matrix adhesion processes, and agents interfering with the intracellular fibrillar system of fibroblasts.

\section{Authors' affiliations}

O Sánchez-Pernaute, R Largo, E Calvo, M A Alvarez-Soria, J Egido, G Herrero-Beaumont, Inflammation Research Unit, Rheumatology Section, Fundación Jiménez Díaz, Universidad Autónoma de Madrid, Spain

\section{REFERENCES}

1 Firestein GS. Etiology and pathogenesis of rheumatoid arthritis. In: Ruddy S, Harris ED, Sledge CB, eds. Kelley's textbook of rheumatology. Philadelphia: Saunders, 2000:921-66.

2 Firestein GS, Zvaifler NJ. How important are T cells in chronic rheumatoid synovitis? II. T cell-independent mechanisns from beginning to end. Arthritis Rheum 2002;46:298-308.

3 Green M, Marzo-Ortega H, McGonagle D, Wakefield R, Proudman S, Conaghan $\mathrm{P}$, et al. Persistence of mild, early inflammatory arthritis: the importance of disease duration, rheumatoid factor, and the shared epitope. Arthritis Rheum 1999;42:2184-8.

4 Busso N, Hamilton JA. Extravascular coagulation and the plasminogen activator/plasmin system in rheumatoid arthritis. Arthritis Rheum 2002:46:2268-79.

5 Berckmans RJ, Nieuwland R, Tak PP, Boing AN, Romijn FP, Kraan MC, et al. Cell-derived microparticles in synovial fluid from inflamed arthritic joints support coagulation exclusively via a factor VII-dependent mechanism. Arthritis Rheum 2002:46:2857-66.

6 Van de Putte LBA, Hegt VN, Overbeek TE. Activators and inhibitors of fibrinolysis in rheumatoid and nonrheumatoid synovial membranes. Arthritis Rheum 1977;20:671-8

7 Weinberg JB, Pippen AM, Greenberg CS. Extravascular fibrin formation and dissolution in synovial tissue of patients with osteoarthritis and rheumatoid arthritis. Arthritis Rheum 1991;34:996-1005.

8 Vassalli JD, Sappino AP, Belin D. The plasminogen activator/plasmin system. J Clin Invest 1991:88:1067-72.

9 Andersen RB, Gormsen J. Fibrinolytic and fibrin stabilizing activity of synovial membranes. Ann Rheum Dis 1970;29:287-93.

10 Clemmensen I, Donde R, Andersen RB. The primary plasmin inhibitor in rheumatoid synovial fluid. Arthritis Rheum 1977;20:1354-8. 
11 Carmassi F, de Negri F, Morale M, Song KY, Chung SI. Fibrin degradation in the synovial fluid of rheumatoid arthritis patients: a model for extravascular fibrinolysis. Semin Thromb Hemost 1996;22:489-96.

12 Kummer JA, Abbink JJ, de Boer JP, Roem D, Nieuwenhuys EJ, Kamp AM, et al. Analysis of intraarticular fibrinolytic pathways in patients with inflammatory and noninflammatory joint diseases. Arthritis Rheum 1992;35:884-93.

13 Braat EA, Jie AF, Ronday HK, Beekman B, Rijken DC. Urokinase-mediated fibrinolysis in the synovial fluid of rheumatoid arthritis patients may be affected by the inactivation of single chain urokinase type plasminogen activator by thrombin. Ann Rheum Dis 2000;59:315-18.

14 Ronday HK, Smits HH, Van Muijen GNP, Pruszczynski MSM, Dolhain RJEM, Van Langelaan EJ, et al. Difference in expression of the plasminogen activation system in synovial tissue of patients with rheumatoid arthritis and ostearthritis. Br J Rheumatol 1996;35:416-23.

15 Zacharski LR, Brown FE, Memoli VA, Kisiel W, Kudryk BJ, Rousseau SM, et al. Pathways of coagulation activation in situ in rheumatoid synovial tissue. Clin Immunol Immunopathol 1992;63:155-62.

16 Caughey DE, Highton TC. Components of the fibrinolytic system in synovial joints. Normal bovine compared with normal and abnormal human synovial joints. Ann Rheum Dis 1967;26:297-305.

17 Clemmensen I, Holund B, Andersen RB. Fibrin and fibronectin in rheumatoid synovial membrane and rheumatoid synovial fluid. Arthritis Rheum 1983;26:479-85.

18 Rothschild BM, Thompson LD, Pifer DD, Chesney CM. Perturbation of protease inhibitors and substrates in inflammatory arthritis. Semin Thromb Hemost 1985;11:394-404.

19 Sánchez-Pernaute O, López-Armada MJ, Calvo E, Díez-Ortego I, Largo R, Egido J, et al. Fibrin generated in the synovial fluid activates intimal cells from their apical surface. A sequential morphologic study in antigen induced arthritis. Rheumatology (Oxford) 2003;42:19-25.

20 Corbett SA, Lee L, Wilson CL, Schwarzbaver JE. Covalent cross-linking of fibronectin to fibrin is required for maximal cell adhesion to a fibronectinfibrin matrix. J Biol Chem 1997;272:24999-5005.

21 Scott DL, Almond TJ, Walton KW, Hunneyball IM. The role of fibronectin in the pathogenesis of antigen-induced arthritis in the rabbit. J Pathol 1983;141:143-56.

22 Corbett SA, Wilson CL, Schwarzbauer JE. Changes in cell spreading and cytoskeletal organization are induced by adhesion to a fibronectin-fibrin matrix. Blood 1996;88:158-66.

23 Sheetz MP, Felsenfeld DP, Galbraith CG. Cell migration: regulation of force on extracellular-matrix-integrin complexes. Trends Cell Biol 1998;8:51-4.

24 Scott DL, Delamere JP, Walton KW. The distribution of fibronectin in the pannus in rheumatoid arthritis. Br J Exp Pathol 1981;62:362-8.

25 Ishikawa H, Hirata S, Andoh Y, Kubo H, Nakagawa N, Nishibayashi Y, et al. An immunohistochemical and immunoelectron microscopy study of adhesion molecules in synovial pannus formation in rheumatoid arthritis. Rheumatol Int $1996 ; 16: 53-60$.
26 Dumonde DC, Glynn LE. The production of arthritis in rabbits by an immunological reaction to fibrin. Br J Exp Pathol 1962;43:373-83.

27 Fassbender HG, Gay S. Synovial processes in rheumatoid arthritis. Scand J Rheumatol 1988;76(suppl): 1-7.

28 Konttinen YT, Saari H, Santavirta S, Antti-Poika I, Sorsa T, Nykanen P, et al. Synovial fibroblasts. Scand J Rheumatol 1988;76(suppl):95-103.

29 Shin H, Nakajima T, Kitajima I, Shigeta K, Abeyama K, Imamura T, et al. Thrombin receptor-mediated synovial proliferation in patients with rheumatoid arthritis. Clin Immunol Immunopathol 1995;76:225-33.

30 Fibbi G, Pucci M, Serni U, Cerinic MM, Del Rosso M. Antisense targeting of the urokinase receptor blocks urokinase-dependent proliferation, chemoinvasion, and chemotaxis of human synovial cells and chonrocytes in vitro. Proc Assoc Am Physicians 1998;1 10:340-50.

31 Sarkissian $M$, Lafyatis R. Integrin engagement regulates proliferation and collagenase expression of rheumatoid synovial fibroblasts. J Immunol 1999; 162:1772-9

32 Cirino G, Cicala C, Bucci M, Sorrentino L, Ambrosini G, DeDominicis G, et al. Factor $\mathrm{Xa}$ as an interface between coagulation and inflammation. Molecular mimicry of factor Xa association with effector cell protease receptor-1 induces acute inflammation in vivo. J Clin Invest 1997;99:2446-51.

33 Shin H, Kitajima I, Nakajima T, Shao Q, Tokioka T, Takasaki I, et al. Thrombin receptor mediated signals induce expressions of interleukin 6 and granulocyte colony stimulating factor via NF-kappa B activation in synovial fibroblasts. Ann Rheum Dis 1999;58:55-60.

34 Carmeliet P. Biomedicine. Clotting factors build blood vessels. Science 2001;293: 1602-4

35 Liu X, Piela-Smith TH. Fibrin(ogen)-induced expression of ICAM-1 and chemokines in human synovial fibroblasts. J Immunol 2000; 165:5255-61.

36 Furmaniak-Kazmierczak E, Cooke TD, Manuel R, Scudamore A, Hoogendorn $H$, Giles AR, et al. Studies of thrombin-induced proteoglycan release in the degradation of human and bovine cartilage. J Clin Invest 1994:94:472-80.

37 Bini A, Wu D, Schnuer J, Kudryk BJ. Characterization of stromelysin 1 (MMP-3), matrilysin (MMP-7), and membrane type 1 matrix metalloproteinase (MT1-MMP) derived fibrin(ogen) fragments D-dimer and D-like monomer: $\mathrm{NH} 2$-terminal sequences of late-stage digest fragments. Biochemistry 1999;38:13928-36.

38 Hotary KB, Yana I, Sabeh F, Li XY, Holmbeck K, Birkedal-Hansen H, et al. Matrix metalloproteinases (MMPs) regulate fibrin-invasive activity via MT1MMP-dependent and -independent processes. J Exp Med 2002; 195:295-308

39 Masson-Bessiere C, Sebbag M, Girbal-Neuhauser E, Nogueira L, Vincent C, Senshu $T$, et al. The major synovial targets of the rheumatoid arthritis-specific antifilaggrin autoantibodies are deiminated forms of the $\alpha$ - and $\beta$-chains of fibrin. J Immunol 2001;166:4177-84.

40 Schellekens GA de Jong BA, van den Hoogen FH, van de Putte $L B$, van Venrooii WJ. Citrulline is an essential constituent of antigenic determinants recognized by rheumatoid arthritis-specific autoantibodies. J Clin Invest 1998;101:273-81.

\section{Get published within days of acceptance with ARD}

- We are delighted to announce that the Annals of the Rheumatic Diseases is launching a "publish ahead of print" programme from February 2004. Selected papers will be fast tracked and published online months before they appear in the print journal.

Papers of major significance to the international rheumatology community will be published within days of acceptance. The published article will be the raw accepted manuscript; edited and typeset versions will also be published as soon as they are available.

In addition to being available on ARD Online, the publish ahead of print articles will be searchable through PubMed/Medline-establishing primacy for your work. They will be linked from the ARD Online home page.

$A R D$ 's publish ahead of print programme is unique among the major rheumatology journals - to take advantage of this service submit your papers to Annals of the Rheumatic Diseases using our online submission and review system Bench>Press (http://submitard.bmijournals.com). For further information contact ARD@bmjgroup.com. 